\title{
Estimation of district level TFR of eight EAG states and Assam from NFHS-4, 2015-16
}

Evidence Project

Follow this and additional works at: https://knowledgecommons.popcouncil.org/departments_sbsr-rh How does access to this work benefit you? Let us know!

\section{Recommended Citation}

Evidence Project. 2020. "Estimation of district level TFR of eight EAG states and Assam from NFHS-4, 2015-16." Washington, DC: Population Council, The Evidence Project. 


\section{Estimation of district level TFR of eight EAG states and Assam from NFHS-4, 2015-16}

As there is a push to monitor indicators at the local level, it is important to determine whether surveys designed for national representation can be used at the district level. This paper explores the accuracy and validity of using the NFHS-4, a nationally representative data source, to estimate district-level Total Fertility Rate (TFR) for the eight Empowered Action Group (EAG) states and Assam.

\section{RECOMMENDATIONS}

Data from national level surveys, like the NFHS, can be used to estimate district-level TFR (and potentially other indicators), as long as estimates contain confidence intervals Publishing district level estimates of TFR in future NFHS rounds can facilitate decentralized data access and action around family planning (FP).

District level TFR estimates can be used to inform government flagship programs designed to take on district level approaches. TFR estimates can be utilized by Mission Parivar Vikas, which aims to improve contraceptive use in 8 EAG states

TFR estimates can inform Aspirational Districts Program, that aims to reduce disparities in Human Development Indices among 115 districts. 

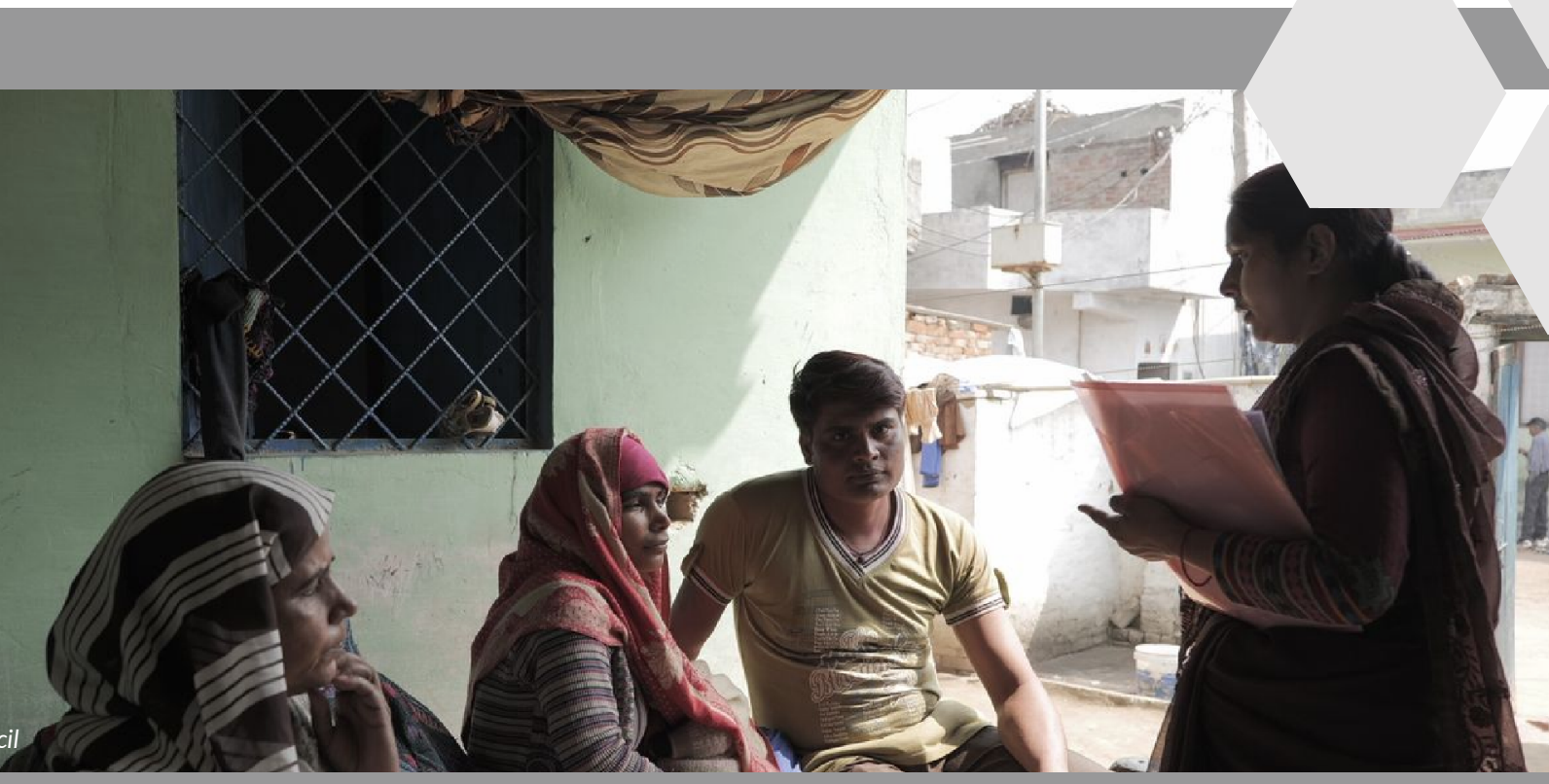

\section{TFR estimates total number of children a woman will have by the end of her reproductive age. This is a significant demographic indicator used to understand impacts of national FP programs. Latest TFRs for these states at the district level are from Annual Health Survey 2012-2013, and were not made available in NFHS-4 district factsheets, but can be calculated from the NFHS}

\section{FINDINGS}

- The greatest range in TFR within a state was seen in Uttar Pradesh where the TFR was 1.58 (95\% Cl: 1.39-1.76) in Lucknow and $4.4(95 \% \mathrm{Cl}$ : 3.96-4.84) in Shrawasti.

- The smallest ranges in TFR variations was seen in Uttarakhand, where Dehradun had the lowest TFR of 1.49 (95\% Cl: 1.32-1.65) and Haridwar had the highest TFR of 2.78 (95\% Cl: 2.55-3.01).

- Many districts in the nine states have a TFR below replacement level, with the exception of Bihar, where the lowest district-level TFR was in Gopalganj, with a rate of 2.55 (95\% Cl: 2.272.83).

\section{METHOD}

The Total Fertity Rate(TFR), the average number of children a woman will have during her reproductive lifespan, was estimated for selected districts and states. TFRs were calculated based on age-specific fertility rates 36 months prior to the survey and birth histories of married women (aged 15-49) from NFHS-4 (2015-16).

\section{RASTA}

RASTA (Research and Analyses for Scientific Transformation and Advancement) is a multiinstitutional research utilization initiative led by Population Council.For more information please contact :

rasta@popcouncil.org

\section{EVIDENCE}

The Evidence Project uses implementation science-the strategic generation, translation, and use of evidence-to strengthen and scale up family planning and reproductive health programs to reduce unintended pregnancies worldwide. The Evidence Project is led by the Population Council

Jayachandran A and F Ram. 2019. "Estimation of district level TFR of eight EAG states and Assam from NFHS-4, 2015-16," Demography India 48(1). Vol. 48, No. 1 (2019), pp. 63-73. Full paper available at http://demographyindia.in/article_document/96/537555_Jayachandran.pdf

The Evidence Project is made possible by the generous support of the American people through the United States Agency for International Development (USAID) under the terms of cooperative agreement no. AIDOAA-A-13-00087. The contents of this document are the sole responsibility of the Evidence Project and Population Council and do not necessarily reflect the views of USAID or the United States Government 